\title{
Perioperative nasal and paranasal sinus considerations in transsphenoidal surgery for pituitary disease
}

\section{Lisa Caulley, Ravindra Uppaluri \& Ian F. Dunn}

To cite this article: Lisa Caulley, Ravindra Uppaluri \& lan F. Dunn (2020) Perioperative nasal and paranasal sinus considerations in transsphenoidal surgery for pituitary disease, British Journal of Neurosurgery, 34:3, 246-252, DOI: 10.1080/02688697.2020.1731424

To link to this article: https://doi.org/10.1080/02688697.2020.1731424

\section{曲 Published online: 25 Feb 2020.}

Submit your article to this journal 준

\section{Џ Article views: 47}

Q View related articles ¿

\section{View Crossmark data ¿`}




\title{
Perioperative nasal and paranasal sinus considerations in transsphenoidal surgery for pituitary disease
}

\author{
Lisa Caulley ${ }^{\mathrm{a}, \mathrm{b}, \mathrm{c}} \mathbb{D}$, Ravindra Uppaluri ${ }^{\mathrm{d}, \mathrm{e} *}$ and Ian F. Dunn ${ }^{\mathrm{a} *}$

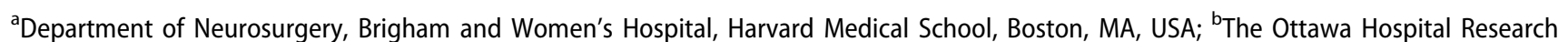 \\ Institute, Ottawa, Canada; 'Department of Epidemiology, Erasmus MC, Rotterdam, The Netherlands; 'Dana Farber Cancer Center, Boston, MA,

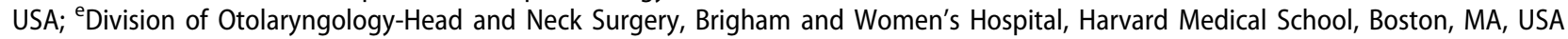

\section{ABSTRACT}

Endoscopic endonasal skull base surgery has emerged as the treatment modality of choice for a range of skull base lesions, particularly pituitary adenomas. However, navigation and manipulation of the nasal corridor and paranasal sinuses requires that surgeons are aware of effective techniques to maximize patient outcomes and avoid sinonasal morbidity postoperatively. This paper is a narrative review aimed to provide an updated and consolidated report on the perioperative management of the nasal corridor and paranasal sinuses in the setting of endoscopic skull base surgery for pituitary disease. Anatomic variants and common surgical techniques are discussed. Post-operative complications are evaluated in detail. Understanding the structural implications of the endonasal approach to the sphenoid is crucial to optimization of the surgical outcomes. We propose guidelines for perioperative management of endoscopic endonasal skull base surgery for pituitary diseases. Standardized treatment algorithms can improve patient satisfaction, and increase the comparability and the quality of reported information across research studies.

\section{ARTICLE HISTORY}

Received 17 February 2019

Accepted 13 February 2020

\section{KEYWORDS}

Minimally invasive surgery; pituitary adenoma; pituitary tumour; pituitary surgery; skull base tumours

\section{Introduction}

By demonstrating comparable outcomes to traditional surgical approaches, endonasal approaches to pituitary tumors have become a dominant method of treatment. ${ }^{1,2}$ Transsphenoidal surgery is now commonly used in the management of sellar lesions, including pituitary tumors, Rathke's cleft cysts, and craniopharyngiomas. ${ }^{3}$ Microscopic visualization of the sphenoid for pituitary disease management became the gold standard for endonasal skull base surgery from the early 1900s, as it obviated the need for brain retraction and complex transcranial interventions. ${ }^{4,5}$ The endoscopic revolution was seeded two decades ago; endoscopic transsphenoidal resection of pituitary tumors was introduced by Jankowski et al. in 1992, popularized in the late 1990s by Jho and Carrau, ${ }^{3,6}$ and continued by Kassam and colleagues in the 2000s. ${ }^{7-10}$ Offering a wider panoramic view and superior visualization of the suprasellar and lateral compartments, as well as the cavernous sinus walls for safe microdissection, endoscopic endonasal transsphendoidal surgery has gained wide acceptance as a safe, minimally-invasive approach to pituitary diseases. ${ }^{11,12}$

In contrast to microscopic transsphenoidal surgery, which is performed via a transseptal subperichondrial approach, endonasal transsphenoidal surgery relies on dissection of the nasal cavity to permit wider access and accommodate four-hand surgery. The technique is commonly performed as a collaboration between otolaryngologists and neurosurgeons and requires a thorough comprehension of the endonasal corridor, anatomic variants and disease pathology that may impact surgical planning. This review is intended to provide an approach to management of the paranasal sinuses and endonasal passage to preserve sinonasal function, reduce complications and optimize interdisciplinary collaboration in endoscopic transsphenoidal approaches to the sella.

\section{Pre-operative considerations}

\section{Patient evaluation and optimization}

A comprehensive history and physical examination to ensure the nasal cavity and paranasal sinuses are optimized prior to surgery is central to appropriate preparation. ${ }^{13}$ Previous sinus surgery does not preclude endonasal skull base surgery but the nature and extent of previous surgical resection should be carefully discussed and evaluated as this may influence reconstructive options or compromise nasal structure.

Physical examination focuses on inspection of the nasal cavity and posterior nasopharynx to visualize the septum, turbinates and identify signs of sinonasal disease. ${ }^{14}$ Anterior rhinoscopy and nasal endoscopy are essential to evaluate the inferior turbinate and anterior nasal septum. It also permits identification of potential obstructions of the nasal corridor, including turbinate hypertrophy, nasal polyps, anatomic variants and inflammatory disease. Identifying and addressing symptomatic pathology in the endonasal corridor provides the opportunity to improve patient's quality of life with regard to nasal function, while treating the primary skull base pathology. ${ }^{13}$

All patients should be screened for signs and symptoms of rhinosinusitis, an established predictor of low post-operative quality of life scores in endonasal skull base surgery. ${ }^{15}$ Rhinosinusitis refers to symptomatic inflammation of the nose 
and paranasal sinuses and can be subclassified based on the duration and etiology of disease. ${ }^{13,16}$ Paranasal sinus inflammation can be precipitated by infection, allergies, immune dysfunction, cilia disorder and structural abnormalities. ${ }^{13}$ Studies have demonstrated favorable outcomes with concurrent management of sinus and pituitary disease. ${ }^{17,18}$ Appropriate management of paranasal sinuses, particularly acute, chronic and fungal rhinosinusitis, has been recommended to ensure healthy sinonasal function in patients undergoing endoscopic skull base surgery. ${ }^{17}$ Acute rhinosinusitis, defined by the American Academy of Otolaryngology as rhinosinusitis of less than four weeks duration, or fungal paranasal sinus disease require staged management of active sinus disease before proceeding with endonasal skull base surgery. ${ }^{16,17}$ Treatment regimens for acute rhinosinusitis include watchful waiting with close follow-up, the use of nasal irrigations, culturedirected antibiotics, decongestants, intranasal corticosteroids, and oral steroids to eradicate infection and stabilize inflammation. ${ }^{16,17,19}$ Fungal paranasal sinus disease, particularly allergic fungal rhinosinusitis and fungal balls, requires endoscopic sinus surgery to eradicate paranasal sinus disease. ${ }^{14}$ In contrast, patients with mild or moderate chronic rhinosinusitis $(>12$ weeks duration) with or without nasal polyposis that is refractory to maximal medical management (including culture-directed antibiotics, nasal irrigations, allergy therapy, oral steroids and decongestants) may be surgically addressed at the time of skullbase surgery without risk of developing an intracranial infection..$^{17,20,21}$

There is limited evidence in the literature on the use of perioperative steroids in the setting of endoscopic skull base surgery for concurrent pituitary disease and chronic paranasal sinus disease or nasal polyposis. Perioperative steroids for functional sinus surgery in management of chronic rhinosinusitis with nasal polyps and allergic fungal sinusitis has been found to improve surgical visualization, decrease operative time and delay polyp recurrence in allergic fungal sinusitis. ${ }^{22}$ Given the favorable outcomes observed in endoscopic sinus surgery, it is worthwhile to consider incorporating perioperative steroids into the multimodal treatment strategy for patients undergoing endoscopic skull base surgery with chronic inflammatory sinus disease, but further research is required to establish the clinical efficacy of steroids in this setting.

\section{Imaging studies}

Pre-operative imaging, including magnetic resonance (MR) imaging of the brain and computed tomography (CT) of the head that includes the sinuses, is essential in surgical planning of the primary skull base lesion and in delineating the bony boundaries, symmetry and aeration of the sphenoid sinus in relation to the sphenoid sinus septum, sella floor and carotid canals. $^{3,23} \mathrm{CT}$ is the current imaging standard for the evaluation of inflammatory diseases of the paranasal sinuses (Figure 1). ${ }^{13}$ Neuroimaging will also serve to guide surgical navigation and planning through complex sinus passages and skull base pathology. ${ }^{14}$

In the endoscopic era, a higher premium is placed on scrutinizing the nasal and sinus anatomy than in conventional microscopic approaches. Anatomic variants commonly encountered in the transsphenoidal approach include anomalies of the nasal septum and turbinates. ${ }^{24}$ Concha bullosa, an aeration of the middle turbinate, ${ }^{14}$ often correlates with patients with highly pneumatized ethmoid sinuses (Figure 2). ${ }^{25} \mathrm{~A}$ paradoxical middle turbinate refers to the abnormal curvature of the

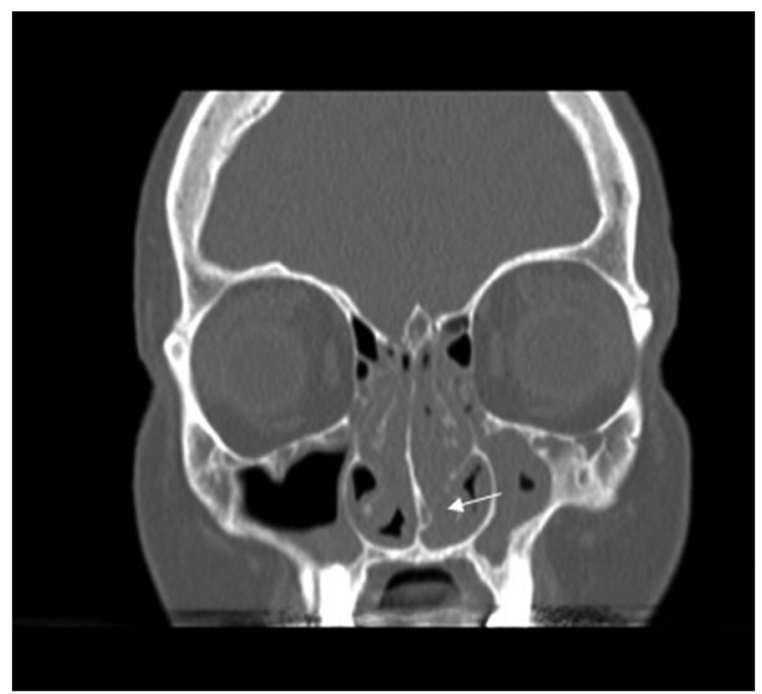

Figure 1. A patient with extensive chronic rhinosinusitis of the maxillary and ethmoid sinuses, nasal polyps and a left septal spur (arrow) in the pre-operative setting for a pituitary adenoma resection.

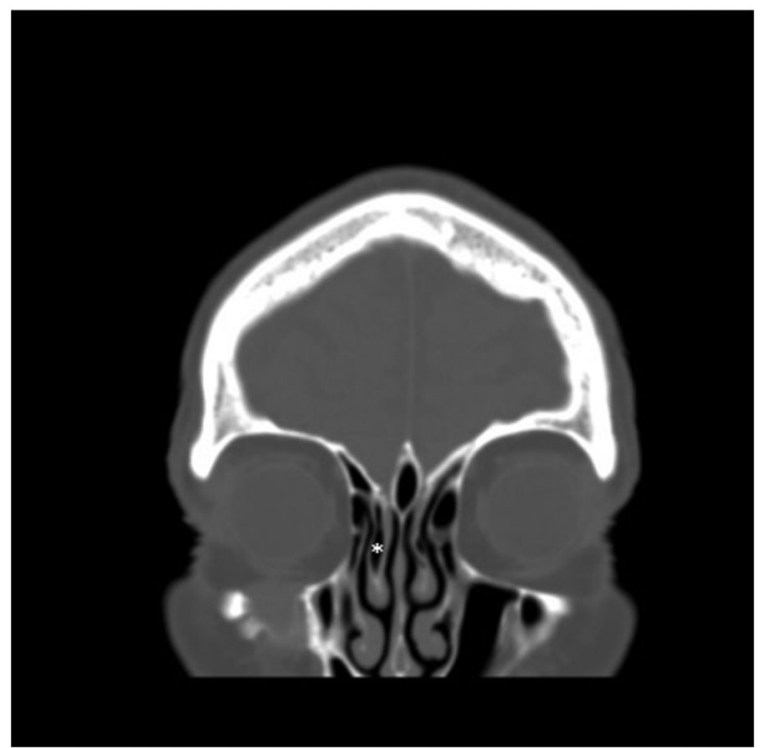

Figure 2. A patient with a concha bullosa (star) on pre-operative evaluation for a pituitary adenoma resection. Partial turbinectomy with excision of the concha bullosa can be considered to provide adequate exposure.

middle turbinate laterally adjacent to the nasal septum, as opposed to its standard medial curvature. ${ }^{14,25}$ Nasal septal deviation defines an asymmetric bowing of the nasal septum that may narrow the nasal corridor and may narrow one nare significantly. ${ }^{14}$ Large studies of septal abnormalities have concluded that non-deviated septums are only present in $7.5-23 \%$ of individuals, indicating a high prevalence of septal deviations in the general population. ${ }^{25}$ These abnormalities, particularly deviations of the caudal septum and bone spurs, may need to be addressed before surgeons can gain access to the nasal corridor. In the setting of clinical evaluation after previous endonasal pituitary surgery, particular attention should be paid to the extent of the septectomy defect and integrity of the nasoseptal flap pedicle. 


\section{Intra-operative considerations}

There are few intranasal anatomical structures that prohibit endonasal skull base surgery, but structures along the endonasal corridor may require resection or mobilization. ${ }^{23}$ Surgical access can involve a range of procedures including, unilateral luxation of the middle turbinate, complete bilateral ethmoidectomy, and may require complementary procedures such as septectomy. ${ }^{23}$ Planned endonasal procedures are intended to develop a large surgical corridor to the posterior nasal cavity that accommodates four-hand surgery, while preserving sinonasal anatomy and function, maintaining ostia patency, minimizing crusting and preventing scar formation. ${ }^{3,13,26}$ The use of careful endoscopic sinus surgical techniques reduces sinonasal morbidity, including crusting, scarring or osteogenesis following trauma, with comparable or superior surgical results. ${ }^{27}$

\section{Management of the turbinates}

Turbinates are outpouchings from the lateral nasal wall that are essential for humidification, filtration, and temperature regulation of nasal airflow and serve as an important surgical landmark. They also provide nasal resistance and contain sensory fibers essential for the perception of nasal airflow, including olfactory fibers in the superior region of the middle and superior turbinates. $^{28,29}$ Surgical manipulation of the turbinates is often required to expand the endonasal corridor. For minimal obstructions, the inferior turbinate may be observed or lateralized to expose the inferior nasal cavity. In rare instances where the inferior turbinate poses a greater degree of obstruction, a partial turbinectomy may be considered. ${ }^{30}$ The middle turbinate can be addressed through lateralization, partial turbinectomy (Figure 3), or complete turbinectomy to maximize the space between the turbinate and nasal septum. ${ }^{3,26}$ Sacrifice of the middle turbinate may be indicated for turbinate dysfunction secondary to polypoid degeneration, concha bullosa, or a paradoxical middle turbinate contributing to nasal obstruction or sinus disease. ${ }^{29-31}$ However, routine turbinectomy for surgical access to the paranasal sinuses has remained controversial. ${ }^{29}$ Middle turbinectomies have not been found to provide significant surgical exposure or freedom as compared to middle turbinate lateralizations. ${ }^{32}$ However, postoperative debridements are easier to perform after middle turbinate resection. In 2001, the American Rhinologic Society released a consensus statement that recommended surgeons avoid sacrifice of the middle turbinate without a satisfactory reason, and consider conservative reduction of the inferior turbinate. ${ }^{30}$

Post-operative Lateralization of the middle turbinate is an adverse sequelae of preservation of the middle turbinate with a potential for scar formation and obstruction of the outflow tract from the maxillary, ethmoid and frontal sinuses. ${ }^{33,34}$ The incidence of middle turbinate lateralization is unclear but it is reported in $10-40 \%$ of endoscopic skull base surgery cases. ${ }^{34}$ Medialization of the middle turbinate intraoperatively with a transseptal suture or insertion of absorbable implants can reduce synechiae formation and lateralization. ${ }^{33,35}$

\section{Management of the nasal septum}

The nasal septum is a midline bony-cartilaginous structure that divides the nasal passages. Manipulation and resection of the nasal septum may be required to provide additional exposure in the transsphenoidal approach. However, surgeons should preserve normal nasal septum when possible to reduce the risk of structural compromise of the nose or septal perforation. ${ }^{14}$ Septoplasties for severe nasal septal deviation that obstructs the endonasal corridor are required infrequently, reported in $1.8 \%$ of cases. ${ }^{36}$ A dorsal and caudal septal segment of $1 \mathrm{~cm}$, termed the L-strut, must be maintained to ensure dorsal and tip support for the nose. ${ }^{14}$ In order to establish binarial exposure of the sphenoid sinus, a posterior septectomy must be performed. ${ }^{32} \mathrm{~A}$ posterior septectomy of $15 \mathrm{~mm}$ provides surgical exposure equivalent to the mean inter-opticocarotid recess. Additional septectomy beyond $20 \mathrm{~mm}$ does not provide significant additional surgical exposure or freedom. ${ }^{32}$ While many surgeons removing the bony septum entirely, it may be profligate in most cases.

\section{Skull base reconstruction}

The ideal technique for closure of the skull base defect that facilitates healing, reduces intracranial infection and prevents cerebrospinal fluid leaks remains controversial. At its inception, skull base closure for endoscopic skull base surgery required reconstruction in several planes, comprised of an inlay, dural and onlay graft. However, as its popularity expanded, studies have demonstrated favorable outcomes in watertight closure with single layer closures. ${ }^{23}$ The materials used to reconstruct the skull base must be carefully selected to reduce foreign body reactions and associated intranasal irritation, inflammation and infection. Dural defects can be reconstructed with allografts or autologous material (fat, turbinate, nasal mucosa, conchal cartilage, temporalis fascia, fascia lata). ${ }^{23}$

The use of a vascularized flap can be considered for dural reconstruction particularly in the setting of high flow cerebrospinal fluid leak encountered intraoperatively. ${ }^{37}$ The nasoseptal flap is an extension of concepts in surgery wherein pedicled vascularized flaps are the gold standard for healing defects. A rotational, vascularized flap based on the posterior septal artery, the nasoseptal flap is unquestionably the workhorse for dural defect closures in endoscopic skull base surgery. ${ }^{14,38,39}$ Nasoseptal flaps are selected for skull base reconstruction in an estimated $25-50 \%$

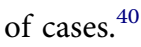

Nasoseptal flaps must be raised prior to exposing the sphenoid, in anticipation of a large defect or an unexpected cerebrospinal fluid leak. In such cases where a nasoseptal flap is not raised, a "rescue" flap approach can be raised at the end of the case, which consists of partially harvesting the most superior and posterior aspect of the flap to protect its pedicle and provide access to the sphenoid face during the approach. The rescue flap also minimizes septum donor site morbidity. ${ }^{41}$ If one is not inclined to harvest a flap initially, it is recommended that the posterior septectomy be performed such that the vascular pedicle of a potential flap is spared. Large skull base defects may be reconstructed with the posterior pedicled inferior turbinate-nasoseptal flap, a large intranasal flap based on the posterior lateral nasal artery. ${ }^{42}$ Resected turbinates can be also used for sellar reconstruction at the end of surgery for small defects and may be considered when the nasoseptal flap is unavailable due to prior surgery. ${ }^{43}$

\section{Packing following endonasal endoscopic skull base surgery}

Surgeons are not obliged to use nasal packing or stents provided there is no heavy bleeding or concern for structural compromise. Packing may be inserted into the nasal cavity after surgery for hemostasis, internal stabilization for the bony and cartilaginous nasal structure and to prevent adhesions or scar formation. ${ }^{27,44}$ 
There are an increasing number of products available for packing and stenting of the nasal cavity but little guidance for recommended materials, duration for packs to remain in place or when placement is indicated. ${ }^{27}$ Nasal packs are nasal foreign bodies that must be removed before inflammatory complications occur. Materials should be easily identified from outside the nose after surgery, and carefully documented and discussed with the patient. The foreign bodies must be firmly secured and follow up must be arranged for removal. ${ }^{27}$ Nasal packing may be removed on the day of surgery or up to 3 days postoperatively. ${ }^{44}$

\section{Post-operative considerations}

\section{Immediate post-operative period}

The nature and duration of post-operative antibiotic therapy remains unclear as several algorithms have been proposed in the literature. ${ }^{45,46}$ Patients typically receive gram-positive cocci coverage for retained nasal foreign bodies, including nasal packing, and to prevent intracranial infection. ${ }^{40}$ Post-operative meningitis is estimated to occur in $0.7-4.5 \% \%$ of endoscopic skull base cases, increasing to $28.5-66.0 \%$ in cases with cerebrospinal fluid leaks. ${ }^{40,47-50}$ Patients should remain on oral antibiotics while nasal packing is in place. Nasal packing should be removed within 48-72 hours of insertion. Nasal splints should be removed 2-3 weeks following nasoseptal flap harvest. A complete evaluation of the nasal cavity should be performed at each interval.

\section{Outpatient follow-up}

Patient education and regular patient visits are key to ensuring maximal sinonasal health in the post-operative period. Follow-up should be coordinated between the neurosurgery and otolaryngology teams to achieve adequate continuity of care. The timing of follow-up is dependent on nasal packing post-operatively, nasal irrigation, degree of nasal crusting, and extent and frequency of debridement. Nasal crusting is the most common postoperative symptoms following skull base surgery, with a median time to absence of crusting of 101.0 days. ${ }^{51}$ Routine nasal saline rinses are recommended to reduce accumulation of nasal debris and facilitate healing (Figure 3). Nasal irrigations should be initiated $72 \mathrm{~h}$ post-operatively, after nasal packing is removed, for passive debridement of nasal crusting and discharge. Active debridement can be initiated between post-operative day 7 and 14 in order to reduce accumulation of nasal debris. Frequency of postoperative visits by otolaryngology is dictated by degree of nasal crusting and frequency of nasal irrigations but should typically be continued on a monthly basis. Effective nasal irrigation can decrease the necessity for in-office debridements. Patients should continue nasal irrigation and routine debridement until satisfactory healing is observed.

\section{Complications}

The popularity of the endonasal approach is credited to its reduced morbidity and rapid recovery in comparison to the transcranial approach. However, the endonasal approach presents a unique set of morbidities associated with the endonasal corridor, paranasal sinuses and nasoseptal flap reconstruction that may still affect quality of life. ${ }^{52}$ The sinonasal outcome test (SNOT)-22 is a disease-specific validated questionnaire used to quantify sinonasal function with a higher score indicating worse outcome. An estimated $27 \%$ of patients score 4.0 or greater

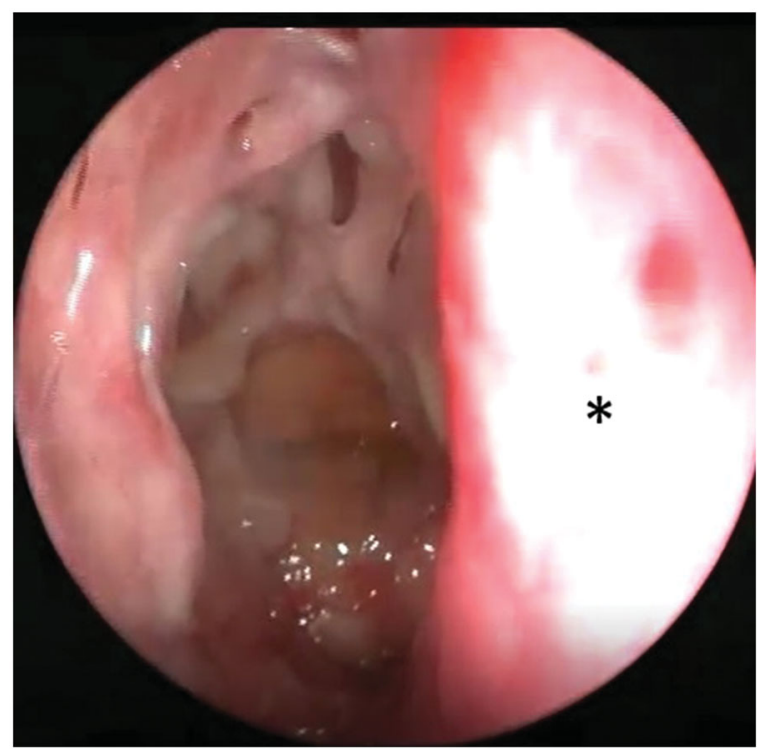

Figure 3. Favorable healing of the nasopharynx surgical corridor following transsphenoidal approach to pituitary adenoma resection. Minimal crusting is seen with adequate saline irrigation and routine debridements (star $=$ remnant anterior septum).

indicating a severe problem relating to loss of smell or taste. Interestingly, SNOT-22 scores are lower in patients who did not have nasal septal flap reconstruction compared with those who did. Overall, mean SNOT-22 scores progressively improve after 1 to 3 months following surgery, with the lowest SNOT-22 scores observed after 6 to 12 months in over $75 \%$ of patients. ${ }^{52}$

Trauma to the nasal corridor and paranasal sinuses is associated with sinonasal morbidity, including sinusitis, synechia, anosmia, epistaxis, septal perforation, nasal congestion, internal nasal valve failure and impaired mucociliary clearance. ${ }^{15,53-59}$ Postoperative rhinosinusitis following transsphenoidal resection of pituitary tumors occurs in an up to $10 \%$ of patients and may persist for an average of 2.9 years. ${ }^{40,60}$ Nasal synechia refers to scar formation between the structures of the lateral nasal wall and the septum or turbinates. The reported incidence of nasal synechaie is $9-20 \%$ in endonasal skull base surgery. ${ }^{61}$ Post-operative epistaxis is a sequela of injury to the sphenopalatine artery. The reported incidence of delayed post-operative epistaxis is $0.6-3.3 \%$, presenting $1-3$ weeks post-operatively. ${ }^{62}$ Conservative management includes bedside nasal packing, balloon tamponading, or cauterization. Embolization of the sphenopalatine artery or internal maxillary artery is recommended when bedside maneuvers fail. ${ }^{62}$ Endonasal surgery may cause changes in nasal volume and resistance leading to increased nasal airflow and hypernasal speech. Hypernasality is a notable complaint in the postoperative setting, particularly amongst patients over age $60 .^{63}$ Septal perforations are an infrequent complication of transsphenoidal surgery, although its occurrence has been reported in the literature. ${ }^{64}$ Careful dissection of the subperichondrial plane in elevation of the nasoseptal flap and assurance of opposing, wellvascularized, mucosal flaps after reconstruction of the septum is critical for preventing septal perforations.

Olfactory dysfunction can be observed following endonasal skull base surgery for several reasons and result in transient or permanent disability. In the early post-operative period, obstructive nasal crusting can prevent odorants from stimulating sensory fibers. ${ }^{59}$ Excessive mucosal sacrifice during an endonasal endoscopic approach may lead to destruction of the olfactory epithelium on the turbinates and septal olfactory mucosa. ${ }^{65}$ Rotenberg 
et $a l .{ }^{66}$ identified a significant decrease in olfactory outcomes following transsphenoidal surgery. Patients administered the University of Pennsylvania Smell Identification Test (UPSIT) reported a mean preoperative UPSIT value of 37.2 (normosmia), and a mean postoperative UPSIT value of 30.8 (moderate hyposmia). The authors hypothesize that olfactory impairment results from use of the nasoseptal flap and recommend judicious use of the nasoseptal flap given the potential for permanent olfactory changes. Patients should be counseled on the possibility of permanent post-operative olfactory changes. ${ }^{66}$ Preservation of the upper nasal septum in elevation of the nasoseptal flap and resection of the nasal septum may reduce the risk of olfactory dysfunction in the post-operative setting.

Aggressive resection of the turbinates, an essential source of respiratory resistance, can result in paradoxical nasal obstruction, so-called empty-nose syndrome. Empty nose syndrome, a poorly recognized but devastating complication of excessive intranasal resections, is an iatrogenic disorder characterized as subjective poor nasal breathing despite a patent nasal airway. ${ }^{67,68}$ A lack of turbinate tissue creates an impaired sensation of nasal airflow while the distal respiratory structures (that is, the pharynx and lungs) and manometric flow studies will continue to indicate a fully patent airway. ${ }^{67}$ This conflicting information can lead patients to report a sensation of suffocating or constant dyspnea, and may result in a preoccupation with nasal breathing, poor concentration (aprosexia nasalis), chronic fatigue and depression. Furthermore, patients may suffer from hyposmia, sleep-disordered breathing, and squamous metaplasia of the remaining nasal mucosa due to excess exposure to dry and cold air. ${ }^{67}$ Empty nose syndrome is a rare, albeit possible, complication following endoscopic skull base surgery, although high quality evidence on this topic is lacking. ${ }^{69-71}$ Management of empty nose syndrome can be challenging. Primary interventions should focus on avoidance of superfluous resection of intranasal structures, a consideration to which surgeons should be particularly conscious of in the setting of endonasal skull base surgery where normal nasal structures are removed. Treatment goals in patients with empty nose syndrome should focus on open dialogue with patients regarding their symptoms, moisturization and reconstruction of nasal structures. $^{67}$ A significant improvement in SNOT-20 and -25 scores following surgical intervention are reported in the majority of patients. However, clinical response varies among patients with up to $21 \%$ reporting only marginal improvement. ${ }^{68}$

\section{Pediatric perioperative considerations}

Endoscopic endonasal skull base surgery has proved to be safe and effective for the management of pediatric pituitary adenomas. ${ }^{72,73}$ However, there is limited evidence to guide perioperative treatment strategies for pediatric patients. A transsphenoidal approach to pediatric skull base lesions requires consideration of age-related differences in endonasal skull base anatomy. Access to the skull base involves navigation through the narrow nasal aperture and entry into an incompletely pneumatized sphenoid sinus. Care should be given to the anatomic restrictions of the nasal passages of pediatric patients, as the nasal pyriform aperature width is significantly smaller in children under age 7 as compared to adults. ${ }^{74}$ Sphenoid sinus pneumatization occurs from age 2 years to age 14 years. $^{75}$ The anterior inferior margin of the sphenoid sinus pneumatizes earlier than the anterior superior margin. ${ }^{74}$ This pneumatization pattern confirms that the medial, anteroinferior margin of the sphenoid bone is the safest entry point for a trans-sphenoidal approach. ${ }^{74}$ Recent studies have shown that reconstruction of skull base defects with a nasoseptal flap is a reliable option in patients over 14 years of age, as these children have adult-sized septums capable of full coverage. $^{76}$ Use of the nasoseptal flap in patients age $10-13$ years requires careful consideration of individual facial analysis and skull base and septal measurements of preoperative imaging. ${ }^{76}$ Post-operative debridements can be challenging in younger patients and may require scheduled operative endonasal surgery.

\section{Conclusions}

Several anatomic and pathologic features must be considered in the endonasal approach to the skull base. We provide a series of recommendations for management of the paranasal sinuses and endonasal corridor to optimize surgical outcomes and patient quality of life (Table 1). Further studies are needed to determine standardized perioperative measures to be taken in endoscopic skull base surgery for pituitary diseases. In order to further advance transsphenoidal management of pituitary diseases,

Table 1. Summary of perioperative management of the paranasal and endonasal corridor in endoscopic transsphenoidal surgery.

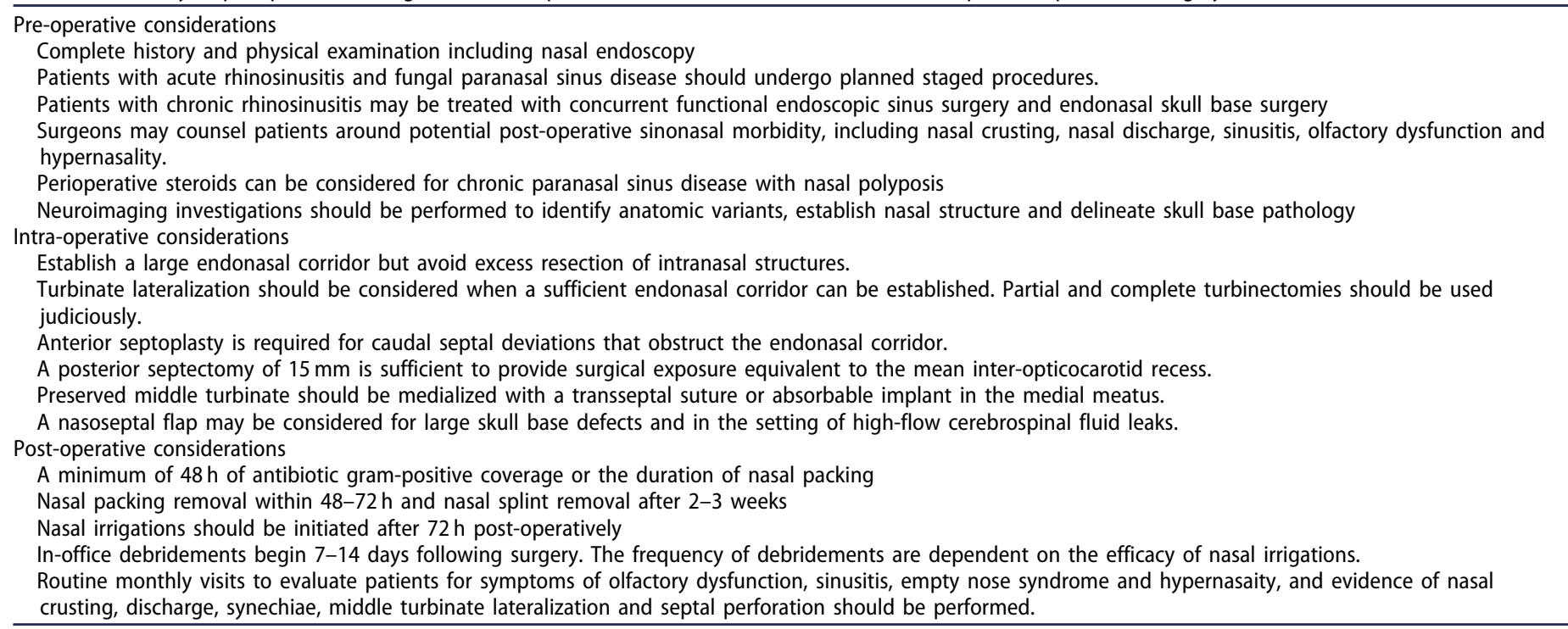


standardized algorithms and outcome metrics are needed to ensure quality assurance. The implementation of a standardized treatment algorithms, as proposed in this manuscript, will improve surgical and patient-reported outcomes, and increase comparability across research studies.

\section{Disclosure statement}

No potential conflict of interest was reported by the author(s).

\section{ORCID}

Lisa Caulley (D) http://orcid.org/0000-0002-9661-4634

\section{References}

1. Ammirati M, Wei L, Ciric I. Short-term outcome of endoscopic versus microscopic pituitary adenoma surgery: a systematic review and metaanalysis. J Neurol Neurosurg Psychiatry 2013;84:843-9.

2. Komotar RJ, Starke RM, Raper DM, Anand VK, Schwartz TH. Endoscopic endonasal compared with microscopic transsphenoidal and open transcranial resection of craniopharyngiomas. World Neurosurg 2012;77:329-41.

3. Jho HD, Carrau RL. Endoscopic endonasal transsphenoidal surgery: experience with 50 patients. J Neurosurg 1997;87:44-51.

4. Wang AJ, Zaidi HA, Laws ED, Jr. History of endonasal skull base surgery. J Neurosurg Sci 2016;60:441-53.

5. Hardy J. Transphenoidal microsurgery of the normal and pathological pituitary. Clin Neurosurg 1969;16:185-217.

6. Jankowski R, Auque J, Simon C, Marchal JC, Hepner H, Wayoff M. Endoscopic pituitary tumor surgery. Laryngoscope 1992;102:198-202.

7. Cavallo LM, Messina A, Gardner P, et al. Extended endoscopic endonasal approach to the pterygopalatine fossa: anatomical study and clinical considerations. Neurosurg Focus 2005;19:E5.

8. Kassam A, Carrau RL, Snyderman CH, Gardner P, Mintz A. Evolution of reconstructive techniques following endoscopic expanded endonasal approaches. Neurosurg Focus 2005;19:1-7.

9. Kassam A, Snyderman CH, Mintz A, Gardner P, Carrau RL. Expanded endonasal approach: the rostrocaudal axis. Part II. Posterior clinoids to the foramen magnum. Neurosurg Focus 2005; 19:E4.

10. Kassam A, Snyderman CH, Mintz A, Gardner P, Carrau RL. Expanded endonasal approach: the rostrocaudal axis. Part I. Crista galli to the sella turcica. Neurosurg Focus 2005;19:E3.

11. Phan K, Xu J, Reddy R, Kalakoti P, Nanda A, Fairhall J. Endoscopic endonasal versus microsurgical transsphenoidal approach for growth hormone-secreting pituitary adenomas-systematic review and metaanalysis. World Neurosurg 2017;97:398-406.

12. Cappabianca P, Cavallo LM, de Divitiis O, Solari D, Esposito F, Colao A. Endoscopic pituitary surgery. Pituitary 2008;11:385-90.

13. Nyquist GG, Rosen MR, Friedel ME, Beahm DD, Farrell CJ, Evans JJ. Comprehensive management of the paranasal sinuses in patients undergoing endoscopic endonasal skull base surgery. World Neurosurg 2014;82:S54-8.

14. Flint PW, Haughey BH, Lund VJ, et al. Cummings otolaryngology. 6th ed. London, UK: Elsevier Health Sciences; 2015.

15. Little AS, Kelly D, Milligan J, et al. Predictors of sinonasal quality of life and nasal morbidity after fully endoscopic transsphenoidal surgery. JNS 2015;122:1458-65.

16. Rosenfeld RM, Piccirillo JF, Chandrasekhar SS, et al. Clinical practice guideline (update): adult sinusitis. Otolaryngol Head Neck Surg 2015; 152:S1-39.

17. Nyquist GG, Friedel ME, Singhal S, et al. Surgical management of rhinosinusitis in endoscopic-endonasal skull-base surgery. Int Forum Allergy Rhinol 2015;5:339-43.

18. Heo KW, Park SK. Rhinologic outcomes of concurrent operation for pituitary adenoma and chronic rhinosinusitis: an early experience. Am J Rhinol 2008;22:533-6.

19. Venekamp RP, Thompson MJ, Hayward G, et al. Systemic corticosteroids for acute sinusitis. Cochrane Database Syst Rev 2011;(12): CD008115.

20. Head K, Chong LY, Hopkins C, Philpott C, Schilder AG, Burton MJ. Short-course oral steroids as an adjunct therapy for chronic rhinosinusitis. Cochrane Database Syst Rev 2016;4:CD011992.
21. Schaberg MR, Shah GB, Evans JJ, Rosen MR. Concomitant transsphenoidal approach to the anterior skull base and endoscopic sinus surgery in patients with chronic rhinosinusitis. J Neurol Surg B Skull B 2013;74:241-6.

22. Poetker DM, Jakubowski LA, Lal D, Hwang PH, Wright ED, Smith TL. Oral corticosteroids in the management of adult chronic rhinosinusitis with and without nasal polyps: an evidence-based review with recommendations. Int Forum Allergy Rhinol 2013;3:104-20.

23. Verillaud B, Bresson D, Sauvaget E, et al. Endoscopic endonasal skull base surgery. Eur Ann Otorhinolaryngol Head Neck Dis 2012;129: 190-6.

24. de Divitiis E, Cappabianca P, Cavallo M. Endoscopic endonasal transsphenoidal approach to the sellar region. In: de Divitiis E, Cappabianca $\mathrm{P}$, eds. Endoscopic endonasal transsphenoidal surgery. Wien: Springer Science \& Business Media; 2012.

25. Neskey D, Eloy JA, Casiano RR. Nasal, septal, and turbinate anatomy and embryology. Otolaryngol Clin North Am 2009;42:193-205, vii.

26. García-Garrigós E, Arenas-Jiménez JJ, Monjas-Cánovas I, et al. Transsphenoidal approach in endoscopic endonasal surgery for skull base lesions: what radiologists and surgeons need to know. RadioGraphics 2015;35:1170-85.

27. Weber RK. Nasal packing and stenting. GMS Curr Top Otorhinolaryngol Head Neck Surg 2009;8:Doc02.

28. Leopold DA, Hummel T, Schwob JE, Hong SC, Knecht M, Kobal G. Anterior distribution of human olfactory epithelium. Laryngoscope 2000;110:417-21.

29. Nyquist GG, Anand VK, Brown S, Singh A, Tabaee A, Schwartz TH. Middle turbinate preservation in endoscopic transsphenoidal surgery of the anterior skull base. Skull Base 2010;20:343-7.

30. Rice DH, Kern EB, Marple BF, Mabry RL, Friedman WH. The turbinates in nasal and sinus surgery: a consensus statement. Ear Nose Throat J 2003;82:82-4.

31. Kennedy DW. Middle turbinate resection: evaluating the issues-should we resect normal middle turbinates? Arch Otolaryngol Head Neck Surg 1998;124:107.

32. Garcia HG, Otten M, Pyfer M, et al. Minimizing septectomy for endoscopic transsphenoidal approaches to the sellar and suprasellar regions: a cadaveric morphometric study. J Neurol Surg B Skull B 2016;77: $479-84$.

33. Weber RK, Hosemann W. Comprehensive review on endonasal endoscopic sinus surgery. GMS Curr Top Otorhinolaryngol Head Neck Surg 2015; 14:Doc08

34. Hosemann W, Draf C. Danger points, complications and medico-legal aspects in endoscopic sinus surgery. GMS Curr Top Otorhinolaryngol Head Neck Surg 2013;12:Doc06.

35. Chen PG, Bassiouni A, Wormald PJ. Incidence of middle turbinate lateralization after axillary flap approach to the frontal recess. Int Forum Allergy Rhinol 2014;4:333-8.

36. Laury AM, Oyesiku NM, Hadjipanayis CG, Delgaudio JM, Wise SK. Incidental sinonasal findings identified during preoperative evaluation for endoscopic transsphenoidal approaches. Am J Rhinol Allergy 2013; 27:202-5.

37. Johansson EW, Selling KE, Nsona $\mathrm{H}$, et al. Integrated paediatric fever management and antibiotic over-treatment in Malawi health facilities: data mining a national facility census. Malar J 2016;15:396.

38. Patel MR, Stadler ME, Snyderman $\mathrm{CH}$, et al. How to choose? Endoscopic skull base reconstructive options and limitations. Skull Base 2010;20:397-404.

39. Hadad G, Bassagasteguy L, Carrau RL, et al. A novel reconstructive technique after endoscopic expanded endonasal approaches: vascular pedicle nasoseptal flap. Laryngoscope 2006;116:1882-6.

40. Johans SJ, Burkett DJ, Swong KN, Patel CR, Germanwala AV. Antibiotic prophylaxis and infection prevention for endoscopic endonasal skull base surgery: our protocol, results, and review of the literature. J Clin Neurosci 2018;47:249-53.

41. Rivera-Serrano CM, Snyderman CH, Gardner P, et al. Nasoseptal "rescue" flap: a novel modification of the nasoseptal flap technique for pituitary surgery. Laryngoscope 2011;121:990-3.

42. Wu P, Li Z, Liu C, Ouyang J, Zhong S. The posterior pedicled inferior turbinate-nasoseptal flap: a potential combined flap for skull base reconstruction. Surg Radiol Anat 2016;38:187-94.

43. Yadav Y, Sachdev S, Parihar V, Namdev H, Bhatele P. Endoscopic endonasal trans-sphenoid surgery of pituitary adenoma. J Neurosci Rural Pract 2012;3:328-37.

44. Weber R, Hochapfel F, Draf W. Packing and stents in endonasal surgery. Rhinology 2000;38:49-62. 
45. Solero CL, DiMeco F, Sampath P, et al. Combined anterior craniofacial resection for tumors involving the cribriform plate: early postoperative complications and technical considerations. Neurosurgery 2000;47: 1296-304. discussion 1304-1295.

46. Kono Y, Prevedello DM, Snyderman CH, et al. One thousand endoscopic skull base surgical procedures demystifying the infection potential: incidence and description of postoperative meningitis and brain abscesses. Infect Control Hosp Epidemiol 2011;32:77-83.

47. Dumont AS, Nemergut EC, 2nd, Jane JA, Jr., Laws ER, Jr. Postoperative care following pituitary surgery. I Intensive Care Med 2005;20:127-40.

48. van Aken MO, Feelders RA, de Marie S, et al. Cerebrospinal fluid leakage during transsphenoidal surgery: postoperative external lumbar drainage reduces the risk for meningitis. Pituitary 2004;7:89-93.

49. Dehdashti AR, Ganna A, Karabatsou K, Gentili F. Pure endoscopic endonasal approach for pituitary adenomas: early surgical results in 200 patients and comparison with previous microsurgical series. Neurosurgery 2008;62:1006-15. discussion 1015-1007.

50. Horowitz G, Fliss DM, Margalit N, Wasserzug O, Gil Z. Association between cerebrospinal fluid leak and meningitis after skull base surgery. Otolaryngol Head Neck Surg 2011;145:689-93.

51. de Almeida JR, Snyderman CH, Gardner PA, Carrau RL, Vescan AD. Nasal morbidity following endoscopic skull base surgery: a prospective cohort study. Head Neck 2011;33:547-51.

52. Pant H, Bhatki AM, Snyderman $\mathrm{CH}$, et al. Quality of life following endonasal skull base surgery. Skull Base 2010;20:035-40.

53. Alobid I, Ensenat J, Marino-Sanchez F, et al. Impairment of olfaction and mucociliary clearance after expanded endonasal approach using vascularized septal flap reconstruction for skull base tumors. Neurosurgery 2013;72:540-6.

54. Cappabianca P, Cavallo LM, Colao A, de Divitiis E. Surgical complications associated with the endoscopic endonasal transsphenoidal approach for pituitary adenomas. J Neurosurg 2002;97:293-8.

55. Charalampaki P, Ayyad A, Kockro RA, Perneczky A. Surgical complications after endoscopic transsphenoidal pituitary surgery. J Clin Neurosci 2009;16:786-9.

56. Hart CK, Theodosopoulos PV, Zimmer LA. Olfactory changes after endoscopic pituitary tumor resection. Otolaryngol Head Neck Surg 2010;142:95-7.

57. Zada G, Kelly DF, Cohan P, Wang C, Swerdloff R. Endonasal transsphenoidal approach for pituitary adenomas and other sellar lesions: an assessment of efficacy, safety, and patient impressions. J Neurosurg 2003;98:350-8

58. Awad AJ, Mohyeldin A, El-Sayed IH, Aghi MK. Sinonasal morbidity following endoscopic endonasal skull base surgery. Clin Neurol Neurosurg 2015;130:162-7.

59. Dolci RLL, Miyake MM, Tateno DA, et al. Postoperative otorhinolaryngologic complications in transnasal endoscopic surgery to access the skull base. Braz J Otorhinolaryngol 2017;83:349-55.

60. Batra PS, Citardi MJ, Lanza DC. Isolated sphenoid sinusitis after transsphenoidal hypophysectomy. Am J Rhinol 2005;19:185-9.
61. Koren I, Hadar T, Rappaport ZH, Yaniv E. Endoscopic transnasal transsphenoidal microsurgery versus the sublabial approach for the treatment of pituitary tumors: endonasal complications. Laryngoscope 1999;109:1838-40.

62. Alzhrani G, Sivakumar W, Park MS, Taussky P, Couldwell WT. Delayed complications after transsphenoidal surgery for pituitary adenomas. World Neurosurg 2018;109:233-41.

63. Kim BY, Shin JH, Kim SW, et al. Hypernasality after using the endoscopic endonasal transsphenoidal approach for skull base tumors. Laryngoscope 2016;126:329-33.

64. Cheng Y, Xue F, Wang TY, et al. Analyses and treatments of postoperative nasal complications after endonasal transsphenoidal resection of pituitary neoplasms. Medicine (Baltimore) 2017;96:e6614.

65. Griffiths CF, Cutler AR, Duong HT, et al. Avoidance of postoperative epistaxis and anosmia in endonasal endoscopic skull base surgery: a technical note. Acta Neurochir 2014;156:1393-401.

66. Rotenberg BW, Saunders S, Duggal N. Olfactory outcomes after endoscopic transsphenoidal pituitary surgery. Laryngoscope 2011;121: 1611-3.

67. Houser SM. Surgical treatment for empty nose syndrome. Arch Otolaryngol Head Neck Surg 2007;133:858-63.

68. Leong SC. The clinical efficacy of surgical interventions for empty nose syndrome: a systematic review. Laryngoscope 2015;125:1557-62.

69. Hardman J, Ahn J, Nirmalananda A. Assessing symptoms of empty nose syndrome in patients following sinonasal and anterior skull base resection. Aust J Otolaryngol 2018;1:9.

70. Maza G, Yanez-Siller JC, Subramaniam S, Otto BA, Daniel PM, Carrau $\mathrm{V}$, Incidence of empty nose syndrome following endoscopic endonasal skull base surgery. 28th Annual Meeting North American Skull Base Society; 2018; The Loews Coronado Bay Coronado, California.

71. Shah K, Guarderas J, Krishnaswamy G. Empty nose syndrome and atrophic rhinitis. Ann Allergy Asthma Immunol 2016;117:217-220.

72. Chivukula S, Koutourousiou M, Snyderman CH, Fernandez-Miranda JC, Gardner PA, Tyler-Kabara EC. Endoscopic endonasal skull base surgery in the pediatric population. J Neurosurg Pediatr 2013;11: 227-241.

73. Banu MA, Rathman A, Patel KS, et al. Corridor-based endonasal endoscopic surgery for pediatric skull base pathology with detailed radioanatomic measurements. Neurosurgery 2014;10:273-293; discussion 293.

74. Tatreau JR, Patel MR, Shah RN, et al. Anatomical considerations for endoscopic endonasal skull base surgery in pediatric patients. Laryngoscope 2010;120:1730-7.

75. Scuderi AJ, Harnsberger HR, Boyer RS. Pneumatization of the paranasal sinuses: normal features of importance to the accurate interpretation of CT scans and MR images. AJR Am J Roentgenol 1993;160: 1101-104.

76. Shah RN, Surowitz JB, Patel MR, et al. Endoscopic pedicled nasoseptal flap reconstruction for pediatric skull base defects. Laryngoscope 2009; 119:1067-75. 